\title{
DNA Methylation of TGF $\beta$ Target Genes: Epigenetic Control of TGF $\beta$ Functional Duality in Liver Cancer
}

\author{
Kevin Bévant ${ }^{1}{ }^{\mathbb{D}}$, Matthis Desoteux ${ }^{1}{ }^{\mathbb{D}}$, Abdel Hady A. Abdel Wahab ${ }^{2}$, Sabrin A. Abdel Wahab ${ }^{3}$, \\ Ayman Mohamed Metwally ${ }^{4, *,+}$ and Cédric Coulouarn ${ }^{1, *,+}(\mathbb{D}$ \\ 1 Centre de Lutte Contre le Cancer Eugène Marquis, Inserm, University of Rennes 1, UMR_S 1242, \\ COSS (Chemistry, Oncogenesis Stress Signaling), 35042 Rennes, France; bevantkevin@gmail.com (K.B.); \\ matthis.desoteux@univ-rennes1.fr (M.D.) \\ 2 Department of Cancer Biology, National Cancer Institute, Cairo University, Cairo 11796, Egypt; \\ abdelhadynci@gmail.com \\ 3 Medical Laboratory Department, Students Hospital, Cairo University, Cairo 11796, Egypt; \\ drsabrin2007@gmail.com \\ 4 Medical Laboratory Technology Department, College of Applied Health Science Technology, Misr University \\ for Science and Technology (MUST), Al-Motamayez District, 6th of October P.O. Box 77, Egypt \\ * Correspondence: ayman.metwally@must.edu.eg (A.M.M.); cedric.coulouarn@inserm.fr (C.C.) \\ + These authors contributed equally to this work.
}

check for

updates

Citation: Bévant, K.; Desoteux, M.; Abdel Wahab, A.H.A.; Abdel Wahab, S.A.; Metwally, A.M.; Coulouarn, C. DNA Methylation of TGF $\beta$ Target Genes: Epigenetic Control of TGF $\beta$ Functional Duality in Liver Cancer. Cells 2021, 10, 2207. https://doi.org/ $10.3390 /$ cells10092207

Academic Editor: Alexander E. Kalyuzhny

Received: 13 July 2021

Accepted: 24 August 2021

Published: 26 August 2021

Publisher's Note: MDPI stays neutral with regard to jurisdictional claims in published maps and institutional affiliations.

Copyright: (c) 2021 by the authors. Licensee MDPI, Basel, Switzerland. This article is an open access article distributed under the terms and conditions of the Creative Commons Attribution (CC BY) license (https:// creativecommons.org/licenses/by/ $4.0 /)$.

\begin{abstract}
Transforming growth factor beta (TGF $\beta$ ) plays a key role in liver carcinogenesis. However, its action is complex, since TGF $\beta$ exhibits tumor-suppressive or oncogenic properties, depending on the tumor stage. At an early stage TGF $\beta$ exhibits cytostatic features, but at a later stage it promotes cell growth and metastasis, as a potent inducer of epithelial to mesenchymal transition (EMT). Here, we evaluated DNA methylation as a possible molecular mechanism switching TGF $\beta$ activity toward tumor progression in hepatocellular carcinoma (HCC). We report that decitabine, a demethylating agent already used in the clinic for the treatment of several cancers, greatly impairs the transcriptional response of SNU449 HCC cells to TGF $\beta$. Importantly, decitabine was shown to induce the expression of EMT-related transcription factors (e.g., SNAI1/2, ZEB1/2). We also report that the promoter of SNAI1 was hypomethylated in poor-prognosis human HCC, i.e., associated with high grade, high AFP level, metastasis and recurrence. Altogether, the data highlight an epigenetic control of several effectors of the TGF $\beta$ pathway in human HCC possibly involved in switching its action toward EMT and tumor progression. Thus, we conclude that epidrugs should be carefully evaluated for the treatment of HCC, as they may activate tumor promoting pathways.
\end{abstract}

Keywords: hepatocellular carcinoma; TGF $\beta$; EMT; epigenetics; DNA methylation

\section{Introduction}

Liver cancer is the fifth most common cancer worldwide and the third most common cause of cancer related death [1]. Hepatocellular carcinoma (HCC) accounts for about 85\% of liver primary tumors, with approximately 626,000 cases diagnosed and 598,000 deaths each year, worldwide [1]. HCC incidence has increased dramatically over the last 20 years, including in high-incidence countries [1]. Most HCC cases (about 80\%) occur in subSaharan Africa and in Eastern Asia. In France, the incidence of HCC has increased in the last 20 years. Nonalcoholic fatty liver diseases represent the fastest growing cause of HCC, not only in France, but also in the USA and the UK [2]. In Egypt, HCC is the second most frequent cause of cancer incidence and mortality in men [1]. Recent investigations have shown the increasing importance of HCV infection in the etiology of HCC, now estimated to account for $>50 \%$ of HCC cases. As an example, $69 \%$ of a cohort of 1328 patients were reported as HCV positive HCC [3]. Thus, Egypt exhibits the highest prevalence of $\mathrm{HCV}$ worldwide, and has experienced a dramatic rise in HCC rates [4]. In contrast to the overall mortality rate, which has declined for most cancer types, liver cancer shows the 
fastest increase in mortality rate [1]. Although significant progress has been made in the management of patients, HCC treatment represents an important clinical challenge [5]. When possible and applied at an early stage, surgery, including tumor resection and liver transplantation, remains the best curative option [6]. Unfortunately, HCC is usually diagnosed at an advanced stage for most patients, thus limiting the therapeutic options [6]. The efficacy of systemic therapies at advanced stages is challenged by the drug-resistant and heterogeneous nature of liver tumors. In addition, common driver mutations (e.g., P53 and CTNNB1) in HCC are not currently drug-treatable [7]. Over the last two decades, functional genomics have allowed a better understanding of the mechanisms underlying HCC carcinogenesis and have unraveled the molecular heterogeneity of HCC tumors [8,9]. Thus, clinically relevant HCC subtypes have been reported [8,10,11]. Notably, we reported good- and poor-prognosis HCC subtypes associated with the activation of the transforming growth factor beta (TGF $\beta$ ) pathway [11].

TGF $\beta$ is a pleiotropic cytokine from the tumor microenvironment that controls fundamental processes, including cell proliferation, apoptosis, differentiation, migration and immunity [12]. Not surprisingly, the TGF $\beta$ pathway is frequently deregulated in cancer, including liver cancers. TGF $\beta$ plays an important role in liver carcinogenesis by contributing to all stages of tumor onset and progression [13-15]. Thus, TGF $\beta$ represents a promising candidate for the development of innovative therapeutic strategies [16]. However, targeting the TGF $\beta$ pathway in cancer is complex, given that TGF $\beta$ exhibits either tumor-suppressive or oncogenic properties, depending on the tumor stage. At an early stage, TGF $\beta$ acts as a powerful cytostatic factor on pre-malignant cells, but at a later stage TGF $\beta$ promotes cell growth and favors metastasis of tumor cells, notably as a potent inducer of epithelial to mesenchymal transition (EMT) [17]. So far, the molecular mechanisms underlying the functional duality of TGF $\beta$ during tumor progression are not fully understood. Several positive and negative regulators (e.g., SARA, SMAD7, SKIL), of which the expression is context dependent, have been shown to tightly regulate the TGF $\beta$ pathway [18]. Thus, modulating the expression or the activity of these regulators and/or effectors associated with tumor-suppressive versus tumor-promoting features of the TGF $\beta$ pathway, may greatly impact the course of tumor progression.

Epigenetic mechanisms, such as chromatin remodeling and DNA methylation, modulate cancer-associated processes (e.g., cell proliferation, invasion, metastasis), and thus HCC onset and progression [19]. These mechanisms are involved in the fine-tuning of gene expression. DNA methylation is catalyzed by DNA methyltransferases (DNMTs), a family of enzymes including DNMT1, DNMT3A, and DNMT3B. DNMTs place a methyl group next to guanosine on $\mathrm{CpG}$ dinucleotides, which frequently build clusters in the promoter regions of genes [20]. Herein, we evaluated DNA methylation as a possible mechanism regulating the activity of the TGF $\beta$ pathway in HCC. We hypothesized that shifting TGF $\beta$ signaling from tumor-suppressive toward pro-metastatic activities may be directly influenced by the degree of methylation of genes involved in the TGF $\beta$ pathway. To test this hypothesis, DNA methylation of TGF $\beta$ regulators and effectors was analyzed in vitro in HCC cells, and further evaluated on resected human HCC samples to determine the clinical relevance of DNA methylation.

\section{Materials and Methods}

\subsection{Human HCC Samples}

Human HCC and non-tumor tissues were isolated from patients undergoing surgery as a primary therapeutic modality during the period from 2001 to 2003 at the National Cancer Institute, Cairo University, Egypt. Department and Institutional approval was obtained. HCC diagnosis was confirmed by histopathological examination of the resected tissues by 2 independent pathologists. Clinical data as well as follow-up studies of the patients were retrospectively collected ( $\mathrm{n}=16$ patients). Patients' consent was obtained before sample collection. The study was conducted according to the Declaration of Helsinki. 


\subsection{Culture of HCC Cells}

HCC cell lines were purchased from ATCC (www.lgcstandards-atcc.org accessed on 12 April 2015) and cultured as previously described [10]. ATCC performed cell lines authentication by STR DNA profiling. Cells were treated with $1 \mathrm{ng} / \mathrm{mL}$ recombinant human TGF 31 (R\&D system, Minneapolis, MN, USA) and 100 $\mu$ M 5-azacytidine (decitabine) (Sigma-Aldrich, St. Louis, MO, USA), alone or in combination. Briefly, overnight serum starvation was applied to all cell cultures. Cells were subsequently incubated in the presence of decitabine (versus control) for $8 \mathrm{~h}$. After $8 \mathrm{~h}$, cells were incubated for $16 \mathrm{~h}$ with TGF $\beta$ (versus control) in the presence or absence of decitabine (Supplementary Figure S1).

\subsection{Gene Expression Profiling}

Total RNA was extracted using a miRNAeasy kit (Qiagen, Courtabeuf, France) according to the manufacturer's instructions. Gene expression profiling was performed using a low-input QuickAmp labeling kit and human SurePrint G3 $8 \times 60 \mathrm{~K}$ microarrays (Agilent Technologies, Santa Clara, CA, USA). Differentially expressed genes were identified by a two-sample univariate $t$ test and a random variance model, as previously described [21]. RT-qPCR was performed using a SYBR Green (Applied Biosystems, Carlsbad, CA, USA) and analyzed as previously described [21].

\subsection{DNA Extraction}

DNA was extracted from 5-25 mg HCC tissues and adjacent non-tumor human tissues using a QIAamp Fast DNA Tissue Kit (Qiagen, cat. no. 51404). For each sample the following cocktail was added: $200 \mu \mathrm{L}$ AVE, $40 \mu \mathrm{L}$ VXL, $1 \mu \mathrm{L}$ DX Reagent, $20 \mu \mathrm{L}$ Proteinase $\mathrm{K}$ and $4 \mu \mathrm{L}$ RNase A (100 mg/mL). Tissue samples were homogenized by vortexing for $5 \mathrm{~min}$, and were then incubated in a thermomixer at $1000 \mathrm{rpm}$ for $10 \mathrm{~min}$ at $56^{\circ} \mathrm{C}$, prior to adding $265 \mu \mathrm{L}$ MVL Buffer. The mixture was added to the QIAamp Mini spin column and processed according to the manufacturer's instructions. DNA concentration and purity were measured using a Nanodrop.

\subsection{Promoter Methylation Analysis}

Promoter methylation for TRFBR2 (EPHS110111-1A), SMAD4 (EPHS106631-1A), SMAD7 (EPHS106615-1A) and SNAI1 (EPHS109344-1A) was studied using the Methyl Screen technology by EpiTect Methyl II Primer Assay kits (Qiagen, cat. 335002). The restriction digestions were performed using the EpiTect Methyl II DNA Restriction Kit (Qiagen, cat. 335452). Amplification was performed using an Applied Biosystem VIIA7 thermocycler. Analysis was performed using the dedicated EpiTect Methyl II PCR Array Microsoft Excel template (www.sabiosciences.com/dna_methylation_data_analysis.php accessed on 20 November 2020). Briefly, CT values were exported to the data analysis sheet and the results (percentage of promoter methylation for each gene) were automatically generated.

\section{Results}

\subsection{Decitabine Impairs the Transcriptional Response of SNU449 HCC Cells to TGF $\beta$}

Gene expression profiling was performed in the SNU449 HCC cell line treated with TGF $\beta(16 \mathrm{~h})$ in the absence or presence of decitabine. As shown in Figure 1A (left panel), 740 probes, corresponding to 623 well-annotated non-redundant genes, were differentially expressed by TGF $\beta$ (i.e., with a fold-change TGF $\beta$ /control FC $>2$ and a $p$-value $<0.001$ ). Validating the gene selection, the highlighted gene signature included well-known TGF $\beta$ targets, including upregulated genes (e.g., COL4A4, IL11, LEFTY2, SERPINE1, SMAD7, SNAI1 or TGFBI) and down-regulated genes (e.g., AQP1, RAB17, SORBS2). Accordingly, Gene Set Enrichment Analysis (GSEA) demonstrated that an experimentally well-defined TGF $\beta$ signature, which we established previously using Tgfbr 2 knockout mice [11], was significantly enriched (NES $=1.59 ; p<0.01)$ in the gene expression profiles of SNU449 cells exposed to TGF $\beta$ (Figure 1B, upper left panel). An independent curated TGF $\beta$ signature entitled "GO_Transforming_Growth_Factor_Beta_Receptor_Signaling_Pathway" from the 
Gene Ontology Consortium was similarly enriched (Figure 1B, lower left panel). The expression of 5 TGF $\beta$-responsive genes (IL11, SERPINE1, SMAD7, SNAI1 and TGFBI) was further validated in other liver cancer cell lines (Supplementary Figure S2A).
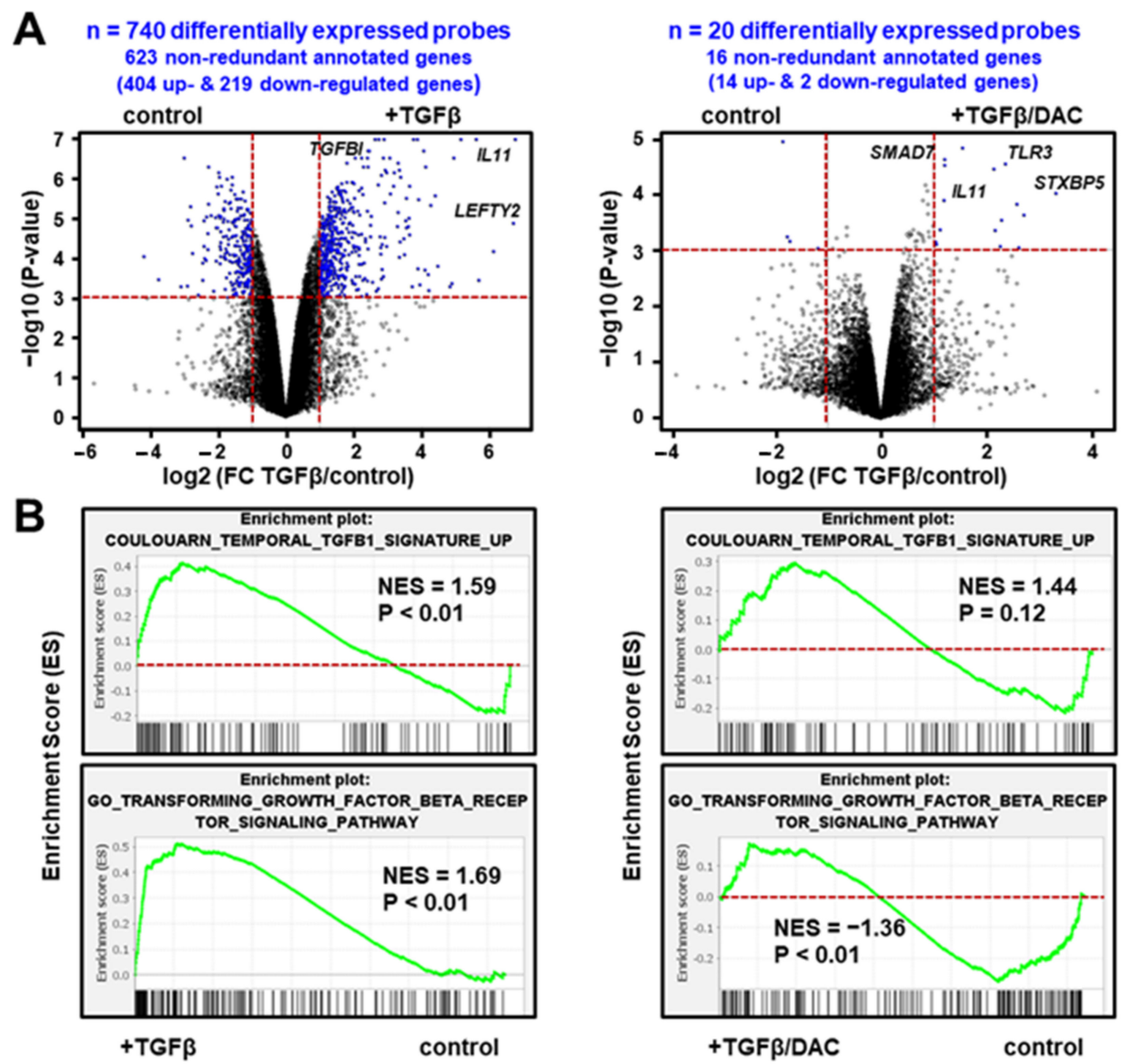

Figure 1. Decitabine impairs the transcriptional response of SNU449 HCC cells to TGF $\beta$. (A) Volcano plot highlighting differentially expressed probes (blue dots) in SNU449 cells treated with TGF $\beta$ $(16 \mathrm{~h})$ in the absence (left panel) or presence (right panel) of decitabine (DAC). Probes were selected based on the significance of the differential expression in the experimental conditions (horizontal red line; $p<0.001$ ) and the level of induction or repression (vertical red lines; fold change $>2$ ). In total, 740 probes were differentially expressed upon TGF $\beta$ treatment in the absence of DAC, but only 20 probes in the presence of DAC, using the same selection criteria. (B) Gene set enrichment analysis (GSEA) using the gene expression profiles of SNU449 cells treated with TGF $\beta$ in the absence (left panels) or presence (right panels) of decitabine. Shown are the enrichment plots of two curated TGF $\beta$-associated gene expression signatures. NES: Normalized Enrichment Score.

Importantly, in the presence of decitabine, only 20 probes, corresponding to 16 wellannotated non-redundant genes, were differentially expressed by TGF $\beta$ using the same statistical criteria (i.e., with a TGF $\beta$ /control FC $>2$ and a $p$-value $<0.001$ ). Among these genes, SMAD7 and IL11 remain upregulated by TGF $\beta$ (Figure 1A, right panel). As shown in Figure 1B (right panels), the curated TGF $\beta$ signatures were not enriched anymore in the gene expression profiles of SNU449 cells exposed to TGF $\beta$ and decitabine. In fact, a statistically significant negative enrichment (NES $=-1.36 ; p<0.01$ ) was observed with the TGF $\beta$ signature established by the Gene Ontology Consortium. In addition, principal component analysis using the whole gene expression profiles (Figure 2A) and clustering analysis based on the expression of 740 probes differentially expressed upon TGF $\beta$ exposure (Figure 2B), demonstrated that the transcriptomic profile of SNU449 cells exposed to TGF $\beta$ in the presence of decitabine (TGF $\beta / D A C)$ was closer to the transcriptomic profile of cells 
exposed to decitabine (DAC) than to TGF $\beta$ or controls. Altogether, these data demonstrate that decitabine greatly impairs the transcriptional response of SNU449 HCC cells to TGF $\beta$.
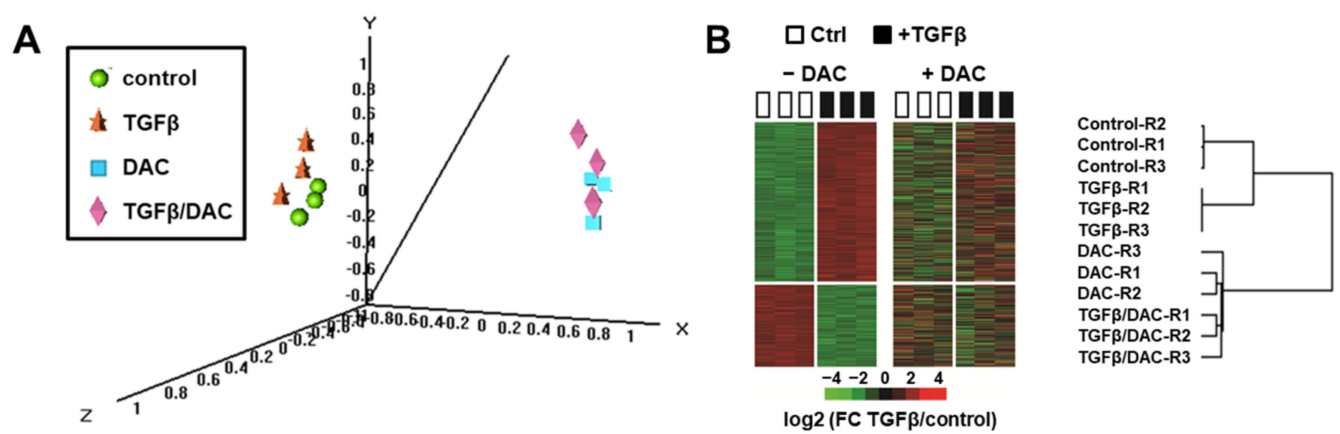

Figure 2. Clustering analysis of gene expression profiles of SNU449 cells upon TGF $\beta$ and decitabine (DAC) treatments. (A) Multidimensional scale (MDS) plot of samples colored by experimental groups, based on the expression of 28,101 probes (global gene expression profiles). (B) Hierarchical clustering analysis based on the expression of 740 probes differentially expressed in SNU449 cells upon TGF $\beta$ treatment $(p<0.001$ and fold-change FC $>2)$ in the absence of decitabine (-DAC, left heatmap). The right heatmap and the dendrogram demonstrate that DAC co-treatment abolished the modulation of TGF $\beta$ responsive genes (R1-3: Replicates 1-3).

\subsection{Decitabine Inhibits the Expression of Members of Canonical SMAD/TGF $\beta$ Signaling Pathway}

Next, we focused on the impact of decitabine on the expression of genes involved in the canonical TGF $\beta$ pathway, including TGF $\beta$ ligands, receptors, intracellular signal transducers and key target genes. As shown in Figure $3 \mathrm{~A}$, decitabine inhibits the induction by TGF $\beta$ of TGFB1 and TGFBR1. Decitabine induces the expression of TGFB2 but has no impact on the expression of TGFBR2. Decitabine drastically inhibits the expression of $S M A D 2-4$, which is critical to transducing the TGF $\beta$ signal from the membrane to the nucleus (Figure 3B). The expression of SMAD7, acting as a TGF $\beta$-induced negative feedback regulator of the signaling pathway, is not affected by decitabine (Figure 3B). Accordingly, key target genes of the canonical SMAD-dependent TGF $\beta$ signaling pathway (e.g., SERPINE1, TGFB1, COL1A1) are repressed in the presence of decitabine (Figure 3C). Interestingly, the induction by TGF $\beta$ of IL11, a cytokine of the IL6/GP130 family involved in multiple cancer hallmarks, including cell migration and invasion [22,23], is greatly enhanced by decitabine (Figure 3C). These data suggest that decitabine suppresses the expression of members of canonical SMAD/TGF $\beta$ signaling pathway and may switch the actions of TGF $\beta$ toward pro-metastatic features. 


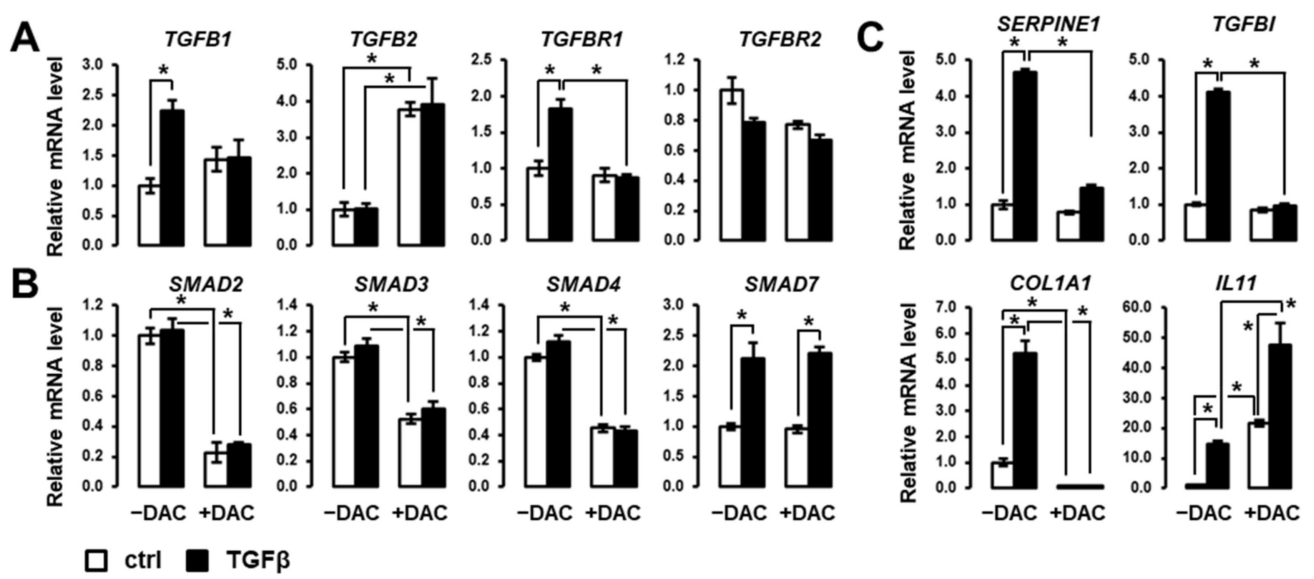

Figure 3. Decitabine greatly impacts the expression of regulators and effectors of the canonical SMAD/TGF $\beta$ signaling pathway. Analysis of the expression of genes encoding (A) TGF $\beta$ ligands and receptors, (B) SMADs transducers and regulators of TGF $\beta$ signaling, and (C) well-known TGF $\beta$ targets, in SNU449 cells treated with TGF $\beta$ (black bars) versus control (white bars) in the absence (left 2 bars) or presence (right 2 bars) of decitabine (DAC). SNU449 HCC cells were treated alone or in combination with $1 \mathrm{ng} / \mathrm{mL}$ TGF $\beta 1$ and $100 \mu \mathrm{M}$ decitabine (DAC) for $24 \mathrm{hrs} .{ }^{*} p<0.05$ $( \pm \mathrm{TGF} \beta, \pm \mathrm{DAC})$.

\subsection{Decitabine Induces the Expression of EMT-Related Transcription Factors in SNU449 Cells}

Based on the above observations, we evaluated the expression of key transcriptional regulators of EMT in SNU449 cells treated with TGF $\beta$ in the absence or presence of decitabine. As shown in Figure 4, decitabine greatly enhances the expression of EMT-associated transcription factors, including SNAI1, SNAI2, ZEB1 and ZEB2. Notably, decitabine enhanced the induction of these transcription factors by TGF $\beta$. These data suggest that these EMT-related transcription factors are repressed by methylation in SNU449 cells.
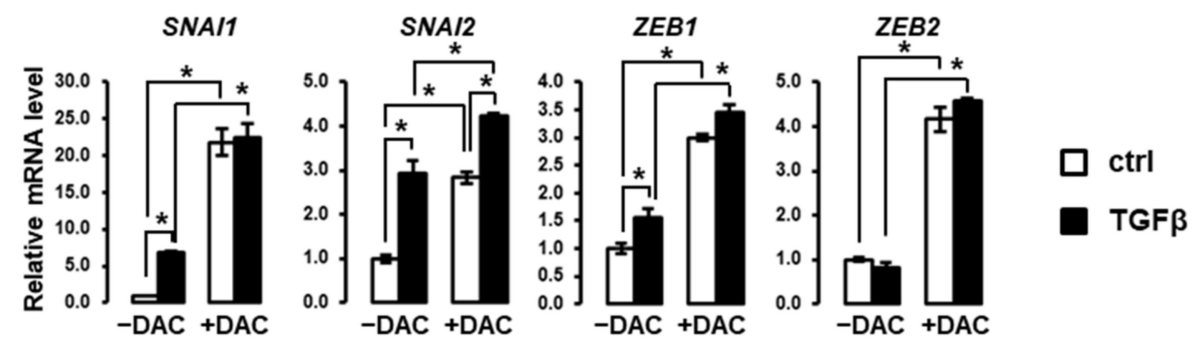

Figure 4. Decitabine enhances the expression of EMT-associated transcription factors. Expression analysis was performed in SNU449 cells treated with TGF $\beta$ (black bars) versus control (white bars) in the absence (left 2 bars) or presence (right 2 bars) of decitabine (DAC). SNU449 cells were treated alone or in combination with $1 \mathrm{ng} / \mathrm{mL}$ TGF $\beta 1$ and $100 \mu \mathrm{M}$ decitabine (DAC) for 24 hrs. ${ }^{*} p<0.05$.

The results were further validated by RT-qPCR in Huh6 and Hep3B HCC cell lines (Supplementary Figure S2B). In addition, we have performed a meta-analysis of a gene expression dataset, which reported the impact of 5-azacitidine on several HCC cell lines (GSE112788). As shown in Supplementary Figure S2C, SNAI1, SNAI2 and ZEB1 as well as IL11 were induced only in some cell lines (particularly HLE and HLF). Very interestingly, we previously reported that these specific cell lines, similar to SNU449, were associated with the so-called late pro-metastatic TGF $\beta$ signature [11]. These data support the idea that epidrugs could be detrimental in specific HCC tumors by activating genes encoding EMT-associated transcription factors. 


\subsection{Promoter Methylation of TGF $\beta$-Associated Genes in SNU449 HCC Cells}

As shown in Figures 3 and 4, the expression of several genes linked to the TGF $\beta$ signaling pathway was modulated in the presence of decitabine. Thus, we directly evaluated the degree of promoter methylation of key candidates in SNU449 HCC cells in the absence or presence of decitabine. The data demonstrated that the promoter of SNAI1 is highly methylated (>60\%) in SNU449 HCC cells (Figure 5). Accordingly, decitabine significantly reduces the percentage of methylated DNA (Figure 5), in agreement with the previously observed induced expression (Figure 4). A similar observation was made for TGFBR2 (Figure 5), although no significant change in expression was observed in the presence of decitabine (Figure 3). The promoters of SMAD4 and SMAD7 were methylated at low levels $(<20 \%)$ in SNU449 HCC cells (Figure 5).
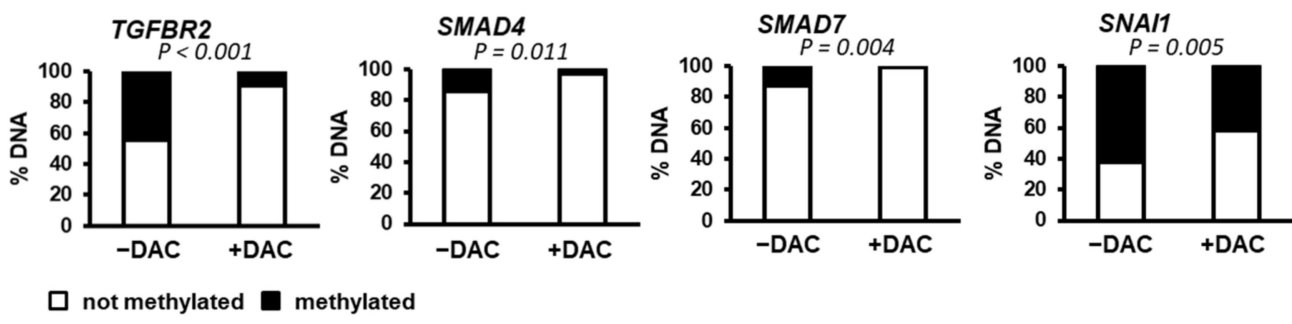

Figure 5. Methylation status of the promoters of genes associated with the TGF $\beta$ pathway. DNA methylation of TGFBR2, SMAD4, SMAD7 and SNAI1 promoters was evaluated in SNU449 HCC cells in the absence (left bar, $-\mathrm{DAC}$ ) or presence of decitabine (right bar, $+\mathrm{DAC}$ ). $p$ value was determined by using a chi-square test (Yates value corrected for continuity).

\subsection{Clinical Relevance of Promoter Methylation of TGF $\beta$-Associated Genes in Human HCC}

Next, we evaluated the specific promoter methylation of the four genes from the TGF $\beta$ signaling pathway (TGFBR2, SMAD4, SMAD7 and SNAI1) evaluated in SNU449 cells in resected human HCC tumors, as well as in the surrounding non-tumor tissues. The median methylation of promoters in HCC was 58\% for TGFBR2 (Range 99.91, min. 0.09, max. 100), $2 \%$ for SMAD4 (Range 99.88, min. 0.12, max. 100), 50\% for SMAD7 (Range 99.99, min. 0.01, max.100) and $40 \%$ for SNAI1 (Range 100, min. 0, max. 100). In the surrounding non-tumor tissues (NT), the median methylation of promoters was 75\% for TGFBR2 (Range 99.68, min. 0.32, max. 100), 51\% for SMAD4 (Range 47.66, min. 26.78, max. 74.44), 23\% for SMAD7 (Range 99.85, min. 0.05, max. 99.9) and 50\% for SNAI1 (Range 99.17, min. 0.57, max. 99.74). No statistically significant difference in gene methylation was observed between NT and HCC groups. Indeed, an important variation in the methylated/unmethylated DNA ratio was observed in human biological samples (Supplementary Figure S3), suggesting that specific methylation profiles could be associated with clinically relevant HCC subtypes. To test this hypothesis, the clinical relevance of promoter methylation of TGFBR2, SMAD4, SMAD7 and SNAI1 genes in HCC was evaluated by correlating the percentage of methylation/non-methylation with clinical and biological parameters, including overall survival, tumor grade, recurrence, metastasis and serum alpha-fetoprotein levels. The median overall survival of the studied cases was 14.1 months (Range 31.5, min. 0.13, max. 31.63) while the median disease-free survival was 9.5 months (Range 16.1, min. 0.33, max. 16.43). No significant correlation was observed between promoter methylation of genes studied and survival (data not shown).

However, as shown in Figure 6, TGFBR2 promoter hypermethylation in HCC is significantly associated with high tumor grade and metastasis $(p<0.001)$ and to a lesser extend with lower alfa fetoprotein level $(p=0.029)$ but no significant correlation is found with recurrence. Higher SMAD4 promoter methylation is significantly associated with high tumor grade, recurrence, metastasis, and elevated AFP $(p<0.01)$. Interestingly, low promoter methylation of $S M A D 7$ was associated with lower tumor grade but high recurrence rate $(p<0.001)$ and metastasis $(p=0.05)$. No significant correlation was found with AFP level (Figure 6). SNAI1 promoter methylation profiles were significantly correlated with all 
parameters. Thus, HCC associated with metastasis and recurrence exhibited significantly lower SNAI1 promoter methylation, reflecting a higher expression. Demethylation of SNAI1 promoter is correlated with elevated AFP levels $(p<0.001)$.
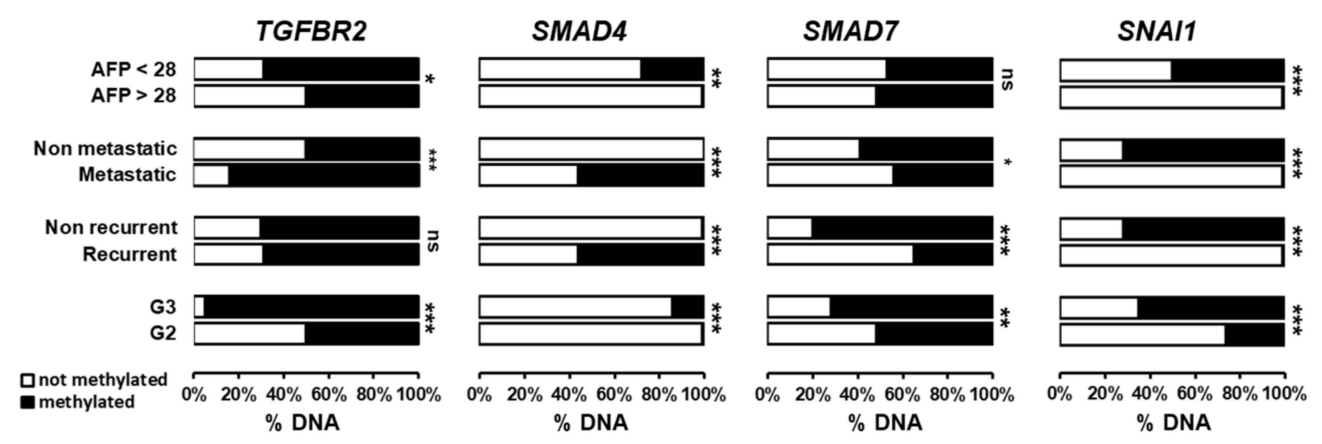

Figure 6. Methylation status of the promoter of TGFBR2, SMAD4, SMAD7 and SNAI1 genes in human HCC tumors and correlation with clinical and biological parameters. The percentage of DNA methylation was correlated with tumor grade (G2 vs. G3), recurrence, metastasis and serum alfa-fetoprotein levels. ${ }^{* *} p<0.001{ }^{* *} p<0.01 ;{ }^{*} p<0.05$; ns $p>0.05$.

\section{Discussion}

Carcinogenesis results in the accumulation of genetic and epigenetic alterations. Previous studies have highlighted the role of DNA methylation in the early steps of carcinogenesis, in particular its contribution to chromosomal instability [24]. Over the past two decades, the genomic landscape of these alterations, including mutation spectrum affecting oncogene-driven signaling pathways, has been highlighted in several cancers, including HCC [25]. Epigenetic alterations have been also shown to contribute to HCC [19]. Supporting a critical epigenetic control of HCC onset and progression, it was recently reported that alterations in DNA methylation occurred in the early pre-neoplastic phases of HCC development and contributed to the deregulation of cancer related genes and pathways [26]. It was also reported that DNA methylation patterns in cirrhotic or fibrotic liver tissues are clinically relevant to identifying those patients at risk of HCC development and de novo recurrence after surgery [26]. We previously reported clinically relevant gene expression signatures in human HCC associated with the dual role of TGF $\beta$ and predicting HCC with better and poor prognosis [11]. In this study, we hypothesized that the functional duality of the TGF $\beta$ pathway in HCC (e.g., tumor-suppressive versus tumor-promoting activities) could depend, at least partly, on the degree of DNA methylation in the promoter of TGF $\beta$-responsive genes and/or regulators of the TGF $\beta$ pathway. We tested this hypothesis in SNU449 HCC cell line and in human HCC.

First, we showed that decitabine and subsequently a global demethylation impaired the TGF $\beta$ signaling and induced the expression of several EMT master genes (e.g. SNAI1/2, $Z E B 1 / 2)$. Previous studies highlighted the importance of DNA methylation on cellular responses to SMADs. Martin et al. showed that TGF $\beta$ treatment induces a change in the methylome of HCC cell lines HepG2 and Huh7 mediated by DNMT3, and that hypermethylation of some core genes increases gene expression [27]. This regulation could explain, at least partially, our observation that global demethylation represses many TGF $\beta$ target genes. Global demethylation and disruption of SMAD signaling has been previously associated with a shift toward an epithelial phenotype [28]. Our results demonstrated that several members of the TGF $\beta$ pathway were subjected to epigenetic regulations in HCC. Indeed, the expression of these genes is greatly influenced by the degree of promoter methylation, as demonstrated in the SNU449 HCC cell line and in patient tumor samples. In addition, our results demonstrated that the degree of methylation in TGF $\beta$ target genes in HCC tumors was a clinically relevant factor associated with the risk of metastasis and tumor recurrence in patients. 
Our results showed that the expression of $S M A D 4$, a member of the canonical TGF $\beta$ signaling responsible for the transmission of the signal from the cell membrane to the nucleus [29,30], is inhibited by decitabine in the SNU449 cell line. A possible explanation is that decitabine activates, by demethylation, other gene(s) which, in turn, act as inhibitors of SMAD4 expression. More interestingly, the results in human HCC indicated that the pattern of $S M A D 4$ methylation was clinically relevant. Thus, hypermethylation of SMAD4 promoter (usually associated with gene inactivation) was predictive of HCC recurrence and metastasis. These results suggested that the epigenetic inhibition of SMAD4 expression by DNA methylation in poor-prognosis HCC may contribute to the loss of the tumor-suppressive arm of the canonical TGF $\beta$ pathway, as is documented in regard to other tumors, including pancreatic and colorectal carcinoma [31,32]. Indeed, as a tumor suppressor gene, SMAD4 is frequently inactivated in cancer by several mechanisms, mostly by genetic alterations [33] but also by promoter methylation. Thus, although mutations in SMAD4 are rare events in prostate cancer and HCC, methylation of its promotor is commonly detected and associated with reduced expression [34]. It is important to emphasize that HCC samples analyzed in our study derived from patients at early stages, allowing tumor removal by surgery. Accordingly, SMAD4 promoter was mostly unmethylated (i.e., active) and possibly exerting its tumor suppressor role to prevent recurrence and metastasis in these patients $[35,36]$. This observation is in agreement with the tumor suppressive role of the canonical SMAD-dependent TGF $\beta$ pathway in the early stages of HCC $[14,16,37]$. However, a dual function of SMAD4 during the course of HCC onset and progression, where it may exert a tumor-suppressive function at an early stage and an oncogenic function at later stages, should be taken into consideration. Indeed, while the tumor-suppressive functions of SMAD4 are well established in mediating cell cycle arrest and apoptosis, it is clear that SMAD4 is also required for tumor progression, notably by mediating TGF $\beta$-induced expression of EMT transcription factors, such as SNAIL, SLUG, TWIST and ZEB [33,38-40]. In the liver, it was shown that SMAD4 knockdown significantly reduced formation and growth of tumors through SNAIL upregulation, suggesting that TGF $\beta$ promotes EMT in a SMAD4-dependent manner $[33,41]$. Thus, one can expect that the functional duality of the TGF $\beta$ pathway is supported in part by the functional duality of its regulators and effectors.

In regard to $S M A D 7$, which is a negative feedback regulator for the TGF $\beta$ pathway, although its expression was not affected by decitabine in SNU449 cells, we observed that its promoter was hypomethylated (i.e., signaling a possible higher expression/activity) in early stage human HCC, especially in poor-prognosis tumors associated with tumor recurrence. Wang et al. reported similar results where SMAD7 was upregulated in human HCC samples with poor prognosis [42]. SMAD7 was shown to contribute to liver carcinogenesis by activating the YAP/NOTCH signaling cascade and inducing an EMT signature [42]. Park et al. also documented an increased SMAD7 immunoreactivity in advanced, but not in early, HCC [43]. However, conflicting results have been also reported, where a decreased expression of SMAD7 in HCC patients was associated with early recurrence and poor prognosis [44]. In the later study, it seems that the decreased expression of $S M A D 7$ resulted from an indirect effect, notably through the overexpression of miR-216a/217 [44]. The significance of TGFBR2 promoter methylation in our study was not as high as the other markers. A significant association was observed with tumor grade and metastasis but not with recurrence. The association between TGFBR2 low expression and high tumor grade tumor was reported in other studies $[45,46]$. In-depth functional studies will be needed to decipher the correlation between TGFBR2 and the other TGF $\beta$ target genes.

Moreover, our data clearly demonstrated that the expression of EMT-associated transcription factors from the SNAI and ZEB families was greatly enhanced by decitabine in SNU449 cells, suggesting that these genes could be inactivated by promoter methylation. It is possible that the induction of EMT master genes by decitabine is independent of TGF $\beta$ signaling, considering that most of these genes are not induced by TGF $\beta$ in the presence of decitabine. Interestingly, data from the literature indicate that silencing of 
DNMTs is associated with the induction of EMT and stemness in several cell types, including prostate cancer [47], bladder cancer [48], breast cancer [49] and liver cancer [50]. Altogether these data support our hypothesis that reduced activity of DNMTs (either by silencing or pharmacological inhibition) may result in the activation of EMT-associated genes or other tumor-promoting genes. Based on the design of our experiments (i.e., short term cell cultures), no obvious signs of aggressiveness were observed in HCC cells upon simultaneous treatment with decitabine and TGF $\beta$. However, it is conceivable that long term experiments may result in a full EMT phenotype, possibly associated with stemness and drug resistance features. Indeed, data from the literature provide evidence for the significance of epigenetic mechanisms regulating liver cancer stem cells (CSCs), particularly in a context using inhibitors of DNA methyltransferases. Thus, it was demonstrated in human HCC cell lines that inhibition of DNA methylation by zebularine, an inhibitor of DNMT1, resulted in an increase in highly tumorigenic cells within the Side Population (SP) fraction, which exhibited features of CSCs and a gene expression profile predicting a poor clinical outcome (reduced survival and early recurrence) in patients with HCC [51,52]. Accordingly, in human HCC, we observed that a low SNAI1 promoter methylation is a risk factor for tumor recurrence and metastasis. These results underscore demethylation in early stages of liver cancer as a risk factor for tumor progression [53-55]. They also provide critical information that may help to develop a strategy for the treatment of HCC patients according to the epigenetic pattern of genes associated with the TGF $\beta$ pathway.

Epigenetic modifications are able to alter the expression of genes without disturbing the genomic sequence, which makes them promising targets for drugs in cancer treatment [56]. The first FDA-approved epi-drugs were HDAC and DNMT inhibitors for the treatment of hematological malignancies [56,57]. Interestingly, these drugs are now extensively tested in solid tumors, including HCC [58-60]. The effects of DNMT inhibitors on HCC cells have been widely explored. In response to these drugs, tumor suppressor genes are expressed and HCC cells partially retro-differentiated with a higher sensitivity to sorafenib [61]. Thus, current evidence suggests that epi-drugs are promising therapies for HCC patients. Epigenetic modulation has been also recently reported as a novel potential strategy to boost immunotherapy in HCC by stimulating T cell trafficking into tumor microenvironment [62]. However, because of their pleiotropic effects, it is noteworthy to consider the putative adverse effects of these drugs when administered to patients, notably in regard to the modulation of specific cell signaling pathways, as exemplified for the TGF $\beta$ pathway in our study. Indeed, our study highlights the complex influence of epigenetic mechanisms, especially promoter methylation, on the regulation of the TGF $\beta$ pathway, and the consequent complexity of targeting this pathway in cancer. Thus, decitabine may not be the treatment of choice for early-stage HCC, as it may switch the actions of TGF $\beta$ toward pro-metastatic features. This may occur though indirect inhibition of SMAD4 and activation of both SMAD7 and SNAI1, resulting in promotion of EMT and future recurrence and/or metastasis.

\section{Conclusions}

In conclusion, our study observed an epigenetic control of TGF $\beta$ functional duality in liver cancer, SMAD4 demethylation being identified as a tumor-suppressive event possibly preventing tumor metastasis and recurrence in early HCC. In addition, the study suggested that SMAD7 and SNAI1 hypomethylation is associated with tumor recurrence. Decitabine is thought to switch the actions of TGF $\beta$ toward pro-metastatic features by indirect inhibition of SMAD4 expression, and activation of both $S M A D 7$ and SNAI1, resulting in recurrence and metastasis. Thus, decitabine may not be the treatment of choice for early-stage HCC.

Supplementary Materials: The following are available online at https:/ / www.mdpi.com/article/10 .3390/cells10092207/s1, Figure S1: Summary of the experimental study design, Figure S2: Decitabine induces the expression of EMT-associated transcription factors in aggressive HCC cell lines, Figure S3: Methylation profiles of TGF $\beta$-associated genes in human liver cancer. 
Author Contributions: Conceptualization, methodology, validation, formal analysis, investigation, data curation, all; resources, A.H.A.A.W.; sample and data collection, S.A.A.W.; writing-original draft preparation, C.C. and A.M.M.; writing-review and editing, all; supervision, project administration, funding acquisition, C.C. and A.M.M. All authors have read and agreed to the published version of the manuscript.

Funding: This research was funded by Inserm, Université de Rennes 1, Ligue Contre le Cancer (CD22, CD35, CD85), INCa, and ITMO Cancer AVIESAN (Alliance Nationale pour les Sciences de la Vie et de la Santé) dans le cadre du Plan cancer (Non-coding RNA in cancerology: fundamental to translational). K.B. and M.D. were supported by a PhD fellowship from Ligue Contre le Cancer (CD22) and Région Bretagne. This project was developed and supported by Campus France in the framework of the Franco-Egyptian partnership IMHOTEP Hubert Curien program between Univ Rennes 1, Inserm, UMR_S 1242, COSS (Chemistry, Oncogenesis Stress Signaling), Centre de Lutte contre le Cancer Eugène Marquis, Rennes, France and the Faculty of Applied Medical Sciences Misr University for science and technology, 6th October, Egypt (project $\mathrm{N}^{\circ} 39530 \mathrm{VD}$ ).

Institutional Review Board Statement: The study was conducted according to the guidelines of the Declaration of Helsinki, and approved by the Institutional Review Board of the Faculty of Applied Medical Sciences, Misr University for science and Technology, Egypt.

Informed Consent Statement: Informed consent was obtained from all subjects involved in the study.

Data Availability Statement: The data that support the findings of this study are available from the corresponding authors, [AMM and CC], upon reasonable request.

Conflicts of Interest: The authors declare no conflict of interest.

\section{References}

1. Bray, F.; Ferlay, J.; Soerjomataram, I.; Siegel, R.L.; Torre, L.A.; Jemal, A. Global cancer statistics 2018: GLOBOCAN estimates of incidence and mortality worldwide for 36 cancers in 185 countries. CA Cancer J. Clin. 2018, 68, 394-424. [CrossRef]

2. Huang, D.Q.; El-Serag, H.B.; Loomba, R. Global epidemiology of NAFLD-related HCC: Trends, predictions, risk factors and prevention. Nat. Rev. Gastroenterol. Hepatol. 2021, 18, 223-238. [CrossRef]

3. El-Zayadi, A.R.; Badran, H.M.; Barakat, E.M.; Attia Mel, D.; Shawky, S.; Mohamed, M.K.; Selim, O.; Saeid, A. Hepatocellular carcinoma in Egypt: A single center study over a decade. World J. Gastroenterol. 2005, 11, 5193-5198. [CrossRef] [PubMed]

4. Lehman, E.M.; Wilson, M.L. Epidemiology of hepatitis viruses among hepatocellular carcinoma cases and healthy people in Egypt: A systematic review and meta-analysis. Int. J. Cancer 2009, 124, 690-697. [CrossRef]

5. Haber, P.K.; Puigvehi, M.; Castet, F.; Lourdusamy, V.; Montal, R.; Tabrizian, P.; Buckstein, M.; Kim, E.; Villanueva, A.; Schwartz, M.; et al. Evidence-based management of HCC: Systematic review and meta-analysis of randomized controlled trials (2002-2020). Gastroenterology 2021, 161, 879-898. [CrossRef] [PubMed]

6. European Association for the Study of the Liver. EASL Clinical Practice Guidelines: Management of hepatocellular carcinoma. J. Hepatol. 2018, 69, 182-236. [CrossRef]

7. Llovet, J.M.; Hernandez-Gea, V. Hepatocellular carcinoma: Reasons for phase III failure and novel perspectives on trial design. Clin. Cancer Res. 2014, 20, 2072-2079. [CrossRef] [PubMed]

8. Rebouissou, S.; Nault, J.C. Advances in molecular classification and precision oncology in hepatocellular carcinoma. J. Hepatol. 2020, 72, 215-229. [CrossRef] [PubMed]

9. Bevant, K.; Coulouarn, C. Landscape of genomic alterations in hepatocellular carcinoma: Current knowledge and perspectives for targeted therapies. Hepatobiliary Surg. Nutr. 2017, 6, 404-407. [CrossRef]

10. Allain, C.; Angenard, G.; Clement, B.; Coulouarn, C. Integrative Genomic Analysis Identifies the Core Transcriptional Hallmarks of Human Hepatocellular Carcinoma. Cancer Res. 2016, 76, 6374-6381. [CrossRef] [PubMed]

11. Coulouarn, C.; Factor, V.M.; Thorgeirsson, S.S. Transforming growth factor-beta gene expression signature in mouse hepatocytes predicts clinical outcome in human cancer. Hepatology 2008, 47, 2059-2067. [CrossRef]

12. David, C.J.; Massague, J. Contextual determinants of TGFbeta action in development, immunity and cancer. Nat. Rev. Mol. Cell Biol. 2018, 19, 419-435. [CrossRef] [PubMed]

13. Dropmann, A.; Dediulia, T.; Breitkopf-Heinlein, K.; Korhonen, H.; Janicot, M.; Weber, S.N.; Thomas, M.; Piiper, A.; Bertran, E.; Fabregat, I.; et al. TGF-beta1 and TGF-beta2 abundance in liver diseases of mice and men. Oncotarget 2016, 7, 19499-19518. [CrossRef] [PubMed]

14. Fabregat, I.; Moreno-Caceres, J.; Sanchez, A.; Dooley, S.; Dewidar, B.; Giannelli, G.; Ten Dijke, P.; IT-LIVER Consortium. TGF-beta signalling and liver disease. FEBS J. 2016, 283, 2219-2232. [CrossRef] [PubMed]

15. Dewidar, B.; Meyer, C.; Dooley, S.; Meindl-Beinker, A.N. TGF-beta in Hepatic Stellate Cell Activation and Liver FibrogenesisUpdated 2019. Cells 2019, 8, 1419. [CrossRef] [PubMed] 
16. Giannelli, G.; Mikulits, W.; Dooley, S.; Fabregat, I.; Moustakas, A.; ten Dijke, P.; Portincasa, P.; Winter, P.; Janssen, R.; Leporatti, S.; et al. The rationale for targeting TGF-beta in chronic liver diseases. Eur. J. Clin. Invest. 2016, 46, 349-361. [CrossRef] [PubMed]

17. Ikushima, H.; Miyazono, K. TGFbeta signalling: A complex web in cancer progression. Nat. Rev. Cancer 2010, 10, 415-424. [CrossRef]

18. Massague, J. TGFbeta signalling in context. Nat. Rev. Mol. Cell Biol. 2012, 13, 616-630. [CrossRef]

19. Fernandez-Barrena, M.G.; Arechederra, M.; Colyn, L.; Berasain, C.; Avila, M.A. Epigenetics in hepatocellular carcinoma development and therapy: The tip of the iceberg. JHEP Rep. 2020, 2, 100167. [CrossRef]

20. Nishiyama, A.; Nakanishi, M. Navigating the DNA methylation landscape of cancer. Trends Genet. 2021. [CrossRef] [PubMed]

21. Merdrignac, A.; Angenard, G.; Allain, C.; Petitjean, K.; Bergeat, D.; Bellaud, P.; Fautrel, A.; Turlin, B.; Clement, B.; Dooley, S.; et al. A novel transforming growth factor beta-induced long noncoding RNA promotes an inflammatory microenvironment in human intrahepatic cholangiocarcinoma. Hepatol. Commun. 2018, 2, 254-269. [CrossRef]

22. Johnstone, C.N.; Chand, A.; Putoczki, T.L.; Ernst, M. Emerging roles for IL-11 signaling in cancer development and progression: Focus on breast cancer. Cytokine Growth Factor Rev. 2015, 26, 489-498. [CrossRef] [PubMed]

23. Jones, S.A.; Jenkins, B.J. Recent insights into targeting the IL-6 cytokine family in inflammatory diseases and cancer. Nat. Rev. Immunol. 2018, 18, 773-789. [CrossRef] [PubMed]

24. Eden, A.; Gaudet, F.; Waghmare, A.; Jaenisch, R. Chromosomal instability and tumors promoted by DNA hypomethylation. Science 2003, 300, 455. [CrossRef] [PubMed]

25. Zucman-Rossi, J.; Villanueva, A.; Nault, J.C.; Llovet, J.M. Genetic Landscape and Biomarkers of Hepatocellular Carcinoma. Gastroenterology 2015, 149, 1226-1239. [CrossRef]

26. Ding, X.; He, M.; Chan, A.W.H.; Song, Q.X.; Sze, S.C.; Chen, H.; Man, M.K.H.; Man, K.; Chan, S.L.; Lai, P.B.S.; et al. Genomic and Epigenomic Features of Primary and Recurrent Hepatocellular Carcinomas. Gastroenterology 2019, 157, 1630-1645. [CrossRef] [PubMed]

27. Martin, M.; Ancey, P.B.; Cros, M.P.; Durand, G.; Le Calvez-Kelm, F.; Hernandez-Vargas, H.; Herceg, Z. Dynamic imbalance between cancer cell subpopulations induced by transforming growth factor beta (TGF-beta) is associated with a DNA methylome switch. BMC Genom. 2014, 15, 435. [CrossRef] [PubMed]

28. Galle, E.; Thienpont, B.; Cappuyns, S.; Venken, T.; Busschaert, P.; Van Haele, M.; Van Cutsem, E.; Roskams, T.; van Pelt, J.; Verslype, C.; et al. DNA methylation-driven EMT is a common mechanism of resistance to various therapeutic agents in cancer. Clin. Epigenet. 2020, 12, 27. [CrossRef]

29. Heldin, C.H.; Miyazono, K.; ten Dijke, P. TGF-beta signalling from cell membrane to nucleus through SMAD proteins. Nature 1997, 390, 465-471. [CrossRef]

30. Papoutsoglou, P.; Louis, C.; Coulouarn, C. Transforming Growth Factor-Beta (TGFbeta) Signaling Pathway in Cholangiocarcinoma. Cells 2019, 8, 960. [CrossRef] [PubMed]

31. Huang, W.; Navarro-Serer, B.; Jeong, Y.J.; Chianchiano, P.; Xia, L.; Luchini, C.; Veronese, N.; Dowiak, C.; Ng, T.; Trujillo, M.A.; et al. Pattern of Invasion in Human Pancreatic Cancer Organoids Is Associated with Loss of SMAD4 and Clinical Outcome. Cancer Res. 2020, 80, 2804-2817. [CrossRef] [PubMed]

32. Oyanagi, H.; Shimada, Y.; Nagahashi, M.; Ichikawa, H.; Tajima, Y.; Abe, K.; Nakano, M.; Kameyama, H.; Takii, Y.; Kawasaki, T.; et al. SMAD4 alteration associates with invasive-front pathological markers and poor prognosis in colorectal cancer. Histopathology 2019, 74, 873-882. [CrossRef] [PubMed]

33. Zhao, M.; Mishra, L.; Deng, C.X. The role of TGF-beta/SMAD4 signaling in cancer. Int. J. Biol. Sci. 2018, 14, 111-123. [CrossRef] [PubMed]

34. Aitchison, A.A.; Veerakumarasivam, A.; Vias, M.; Kumar, R.; Hamdy, F.C.; Neal, D.E.; Mills, I.G. Promoter methylation correlates with reduced Smad4 expression in advanced prostate cancer. Prostate 2008, 68, 661-674. [CrossRef] [PubMed]

35. Hahn, S.A.; Schutte, M.; Hoque, A.T.; Moskaluk, C.A.; da Costa, L.T.; Rozenblum, E.; Weinstein, C.L.; Fischer, A.; Yeo, C.J.; Hruban, R.H.; et al. DPC4, a candidate tumor suppressor gene at human chromosome 18q21.1. Science 1996, 271, 350-353. [CrossRef] [PubMed]

36. Liu, Y.; Sheng, J.; Dai, D.; Liu, T.; Qi, F. Smad4 acts as tumor suppressor by antagonizing lymphangiogenesis in colorectal cancer. Pathol. Res. Pract. 2015, 211, 286-292. [CrossRef]

37. Matsuzaki, K.; Seki, T.; Okazaki, K. TGF-beta signal shifting between tumor suppression and fibro-carcinogenesis in human chronic liver diseases. J. Gastroenterol. 2014, 49, 971-981. [CrossRef]

38. Valcourt, U.; Kowanetz, M.; Niimi, H.; Heldin, C.H.; Moustakas, A. TGF-beta and the Smad signaling pathway support transcriptomic reprogramming during epithelial-mesenchymal cell transition. Mol. Biol. Cell 2005, 16, 1987-2002. [CrossRef]

39. Yuan, T.; Chen, Z.; Yan, F.; Qian, M.; Luo, H.; Ye, S.; Cao, J.; Ying, M.; Dai, X.; Gai, R.; et al. Deubiquitinating enzyme USP10 promotes hepatocellular carcinoma metastasis through deubiquitinating and stabilizing Smad4 protein. Mol. Oncol. 2020, 14, 197-210. [CrossRef]

40. Vincent, T.; Neve, E.P.; Johnson, J.R.; Kukalev, A.; Rojo, F.; Albanell, J.; Pietras, K.; Virtanen, I.; Philipson, L.; Leopold, P.L.; et al. A SNAIL1-SMAD3/4 transcriptional repressor complex promotes TGF-beta mediated epithelial-mesenchymal transition. Nat. Cell Biol. 2009, 11, 943-950. [CrossRef] 
41. Moon, H.; Ju, H.L.; Chung, S.I.; Cho, K.J.; Eun, J.W.; Nam, S.W.; Han, K.H.; Calvisi, D.F.; Ro, S.W. Transforming Growth Factor-beta Promotes Liver Tumorigenesis in Mice via Up-regulation of Snail. Gastroenterology 2017, 153, 1378-1391. [CrossRef]

42. Wang, H.; Song, X.; Liao, H.; Wang, P.; Zhang, Y.; Che, L.; Zhang, J.; Zhou, Y.; Cigliano, A.; Ament, C.; et al. Overexpression of Mothers Against Decapentaplegic Homolog 7 Activates the Yes-Associated Protein/NOTCH Cascade and Promotes Liver Carcinogenesis in Mice and Humans. Hepatology 2021, 74, 248-263. [CrossRef]

43. Park, Y.N.; Chae, K.J.; Oh, B.K.; Choi, J.; Choi, K.S.; Park, C. Expression of Smad7 in hepatocellular carcinoma and dysplastic nodules: Resistance mechanism to transforming growth factor-beta. Hepatogastroenterology 2004, 51, 396-400. [PubMed]

44. Xia, H.; Ooi, L.L.; Hui, K.M. MicroRNA-216a/217-induced epithelial-mesenchymal transition targets PTEN and SMAD7 to promote drug resistance and recurrence of liver cancer. Hepatology 2013, 58, 629-641. [CrossRef] [PubMed]

45. Dillard, D.G.; Muller, S.; Cohen, C.; Bloch, D.; Del Gaudio, J.M.; Gal, A.A. High tumor grade in salivary gland mucoepidermoid carcinomas and loss of expression of transforming growth factor beta receptor type II. Arch. Otolaryngol. Head Neck Surg. 2001, 127, 683-686. [CrossRef] [PubMed]

46. Gobbi, H.; Arteaga, C.L.; Jensen, R.A.; Simpson, J.F.; Dupont, W.D.; Olson, S.J.; Schuyler, P.A.; Plummer, W.D., Jr.; Page, D.L. Loss of expression of transforming growth factor beta type II receptor correlates with high tumour grade in human breast in-situ and invasive carcinomas. Histopathology 2000, 36, 168-177. [CrossRef] [PubMed]

47. Lee, E.; Wang, J.; Yumoto, K.; Jung, Y.; Cackowski, F.C.; Decker, A.M.; Li, Y.; Franceschi, R.T.; Pienta, K.J.; Taichman, R.S. DNMT1 Regulates Epithelial-Mesenchymal Transition and Cancer Stem Cells, Which Promotes Prostate Cancer Metastasis. Neoplasia 2016, 18, 553-566. [CrossRef]

48. Wang, X.; Liang, Z.; Xu, X.; Li, J.; Zhu, Y.; Meng, S.; Li, S.; Wang, S.; Xie, B.; Ji, A.; et al. miR-148a-3p represses proliferation and EMT by establishing regulatory circuits between ERBB3/AKT2/c-myc and DNMT1 in bladder cancer. Cell Death Dis. 2016, 7, e2503. [CrossRef] [PubMed]

49. Ateeq, B.; Unterberger, A.; Szyf, M.; Rabbani, S.A. Pharmacological inhibition of DNA methylation induces proinvasive and prometastatic genes in vitro and in vivo. Neoplasia 2008, 10, 266-278. [CrossRef]

50. Jiang, H.; Cao, H.J.; Ma, N.; Bao, W.D.; Wang, J.J.; Chen, T.W.; Zhang, E.B.; Yuan, Y.M.; Ni, Q.Z.; Zhang, F.K.; et al. Chromatin remodeling factor ARID2 suppresses hepatocellular carcinoma metastasis via DNMT1-Snail axis. Proc. Natl. Acad. Sci. USA 2020, 117, 4770-4780. [CrossRef] [PubMed]

51. Marquardt, J.U.; Factor, V.M.; Thorgeirsson, S.S. Epigenetic regulation of cancer stem cells in liver cancer: Current concepts and clinical implications. J. Hepatol. 2010, 53, 568-577. [CrossRef]

52. Marquardt, J.U.; Raggi, C.; Andersen, J.B.; Seo, D.; Avital, I.; Geller, D.; Lee, Y.H.; Kitade, M.; Holczbauer, A.; Gillen, M.C.; et al. Human hepatic cancer stem cells are characterized by common stemness traits and diverse oncogenic pathways. Hepatology 2011, 54, 1031-1042. [CrossRef] [PubMed]

53. Chen, Z.; Zuo, X.; Pu, L.; Zhang, Y.; Han, G.; Zhang, L.; Wu, Z.; You, W.; Qin, J.; Dai, X.; et al. Hypomethylation-mediated activation of cancer/testis antigen KK-LC-1 facilitates hepatocellular carcinoma progression through activating the Notch1/Hes1 signalling. Cell Prolif. 2019, 52, e12581. [CrossRef]

54. Henrique, R.; Jeronimo, C. DNA hypomethylation in plasma as a cancer biomarker: When less is more? Expert Rev. Mol. Diagn. 2014, 14, 419-422. [CrossRef] [PubMed]

55. Wang, W.; Ding, B.; Lou, W.; Lin, S. Promoter Hypomethylation and miR-145-5p Downregulation- Mediated HDAC11 Overexpression Promotes Sorafenib Resistance and Metastasis of Hepatocellular Carcinoma Cells. Front. Cell Dev. Biol. 2020, 8, 724. [CrossRef] [PubMed]

56. Azad, N.; Zahnow, C.A.; Rudin, C.M.; Baylin, S.B. The future of epigenetic therapy in solid tumours-lessons from the past. Nat. Rev. Clin. Oncol. 2013, 10, 256-266. [CrossRef] [PubMed]

57. Berdasco, M.; Esteller, M. Clinical epigenetics: Seizing opportunities for translation. Nat. Rev. Genet. 2019, 20, 109-127. [CrossRef] [PubMed]

58. Bitzer, M.; Horger, M.; Giannini, E.G.; Ganten, T.M.; Worns, M.A.; Siveke, J.T.; Dollinger, M.M.; Gerken, G.; Scheulen, M.E.; Wege, H.; et al. Resminostat plus sorafenib as second-line therapy of advanced hepatocellular carcinoma-The SHELTER study. $J$. Hepatol. 2016, 65, 280-288. [CrossRef]

59. Fan, H.; Lu, X.; Wang, X.; Liu, Y.; Guo, B.; Zhang, Y.; Zhang, W.; Nie, J.; Feng, K.; Chen, M.; et al. Low-dose decitabine-based chemoimmunotherapy for patients with refractory advanced solid tumors: A phase I/II report. J. Immunol. Res. 2014, 2014, 371087. [CrossRef]

60. Yeo, W.; Chan, S.L.; Mo, F.K.; Chu, C.M.; Hui, J.W.; Tong, J.H.; Chan, A.W.; Koh, J.; Hui, E.P.; Loong, H.; et al. Phase I/II study of temsirolimus for patients with unresectable Hepatocellular Carcinoma (HCC)- a correlative study to explore potential biomarkers for response. BMC Cancer 2015, 15, 395. [CrossRef]

61. Gailhouste, L.; Liew, L.C.; Yasukawa, K.; Hatada, I.; Tanaka, Y.; Nakagama, H.; Ochiya, T. Differentiation Therapy by Epigenetic Reconditioning Exerts Antitumor Effects on Liver Cancer Cells. Mol. Ther. 2018, 26, 1840-1854. [CrossRef] [PubMed]

62. Hong, Y.K.; Li, Y.; Pandit, H.; Li, S.; Pulliam, Z.; Zheng, Q.; Yu, Y.; Martin, R.C.G. Epigenetic modulation enhances immunotherapy for hepatocellular carcinoma. Cell Immunol. 2019, 336, 66-74. [CrossRef] [PubMed] 